\title{
Agronomic
}

\section{INFLUÊNCIA DO TAMANHO DA SEMENTE NA QUALIDADE FISIOLÓGICA DA SOJA}

\author{
INFLUENCE OF SEED SIZE ON SOY PHYSIOLOGICAL QUALITY
}

Elisângela Borges Coelho ${ }^{1}$; José Eduardo Barbosa de Souza ${ }^{2}$; Thaís Antônia Martins ${ }^{1}$; Dahyane Pereira dos Santos ${ }^{1}$

${ }^{1}$ Bacharel em Agronomia pela Faculdade Evangélica de Goianésia- elisangelaborgescoelho@gmail.com

2 Docente, Mestre em Agronomia do Curso de Agronomia da Faculdade Evangélica de Goianésia

\section{Info}

Recebido: 03/2019

Publicado: 06/2019

ISSN: 2595-6906

\begin{tabular}{l}
\hline Palavras-Chave \\
Classificação de sementes, \\
germinação e vigor. \\
Keywords: \\
Seed classification, germination and \\
vigor
\end{tabular}

\section{Resumo}

A demanda por sementes de boa qualidade física, fisiológica e sanitária tem aumentado, e os produtores de sementes têm passado a praticar a classificação das sementes de soja por tamanho após o processo de limpeza. Apesar da adoção dos produtores da classificação por tamanho, existe ainda muita controvérsia em relação ao efeito do tamanho da semente de soja no desempenho da cultura. 0 presente trabalho tem por objetivo verificar a influência do tamanho da semente na qualidade fisiológica da soja. Para isso foi utilizada a cultivar de soja, BMX. Bônus IPRO, classificada em três tamanhos: $5 \mathrm{~mm}$; $6 \mathrm{~mm}$ e 7 $\mathrm{mm}$. Foi realizado testes de germinação em canteiro e laboratório e teste do vigor por meio da massa seca de plântula e comprimento de plântula. Constatou-se que as sementes da peneira de $6 \mathrm{~mm}$ apresentaram maiores taxas de germinação nos testes realizados em campo e canteiro. A classificação das sementes possui influência direta sobre a taxa de germinação e vigor das sementes, bem como o tempo de armazenamento da semente.

\section{Abstract}

The demand for seeds of good physical, physiological and sanitary quality has increased, and seed producers have been practicing the classification of soybean seeds by size after the cleaning process. Despite the adoption of the producers of the classification by size, there is still controversy regarding the effect of the size of soybean performance culture. The present work aims to verify the influence of seed size on the physiological quality of soybean. For this, a soybean cultivar, BMX, was used. IPRO bonus, classified in three sizes: $5 \mathrm{~mm} ; 6 \mathrm{~mm}$ and $7 \mathrm{~mm}$. And carried out germination tests on site and laboratory test and force through: dry mass of seedlings, seedling length. It was found that seeds of $6 \mathrm{~mm}$ sieve has higher germination rates in tests on the field site. The classification of seeds has direct influence on the rate of germination and seed vigor and the seed storage. 


\section{INTRODUÇÃO}

Dentre as espécies produtoras de grãos cultivadas no Brasil, a soja (Glycine max L. Merril) é considerada uma das culturas de maior potencial econômico para a comercialização interna e externa. É também uma das mais importantes oleaginosas do mundo (VINHAL-FREITAS et al., 2011).

A soja em grão é destinada principalmente para o setor industrial, cerca de $90 \%$ da produção, onde se realiza o processo de esmagamento, para se produzir farelo de soja, que é um farelo protéico, amplamente utilizado para nutrição animal de aves, suínos e bovinos ou óleo de soja (HIRAKURI; LAZZAROTTO, 2014). Existem previsões de que haja aumento no seu consumo, gerando a necessidade da elevação da produção de soja. Este aumento pode ser obtido de duas formas: através do aumento da área plantada, ou do rendimento por área (SANTOS et al., 2017).

As áreas cultivadas com soja têm apresentado crescimento nas últimas décadas, dados da CONAB (2018) mostram crescimento de 3,4\% da área plantada em 2018 em relação ao ano de 2017, atingindo 35.046,5 milhões de hectares. Desta forma, o mercado torna-se cada vez mais competitivo e globalizado, tornando necessária a realização do gerenciamento eficiente e da utilização de tecnologias, visando reduzir custos e aumentar a produtividade, para que os produtores consigam manter-se no mercado (MOTERLE et al., 2011).

O desenvolvimento de novas técnicas e métodos de produção com o objetivo do aumento da produtividade e qualidade é a preocupação dos segmentos que compõem a cadeia produtiva da agricultura, em especial o da soja. O impacto da utilização de novas cultivares com maior potencial de produtividade e lucratividade está diretamente ligado com a qualidade da semente disponibilizada ao agricultor (VIEIRA \& RAVA, 2000).

O mau desempenho em campo é um dos principais riscos para a produção, caso isso ocorra, é necessário ressemear ou optar por outra cultura, elevando os custos de produção e diminuindo a produtividade. Esse último devido principalmente a alteração da época de semeadura, à não-obtenção de um estande adequado. As sementes consideradas de alto vigor, normalmente apresentam germinação mais rápida e uniforme, sendo capazes de suportar melhor as adversidades do ambiente (BRACCINI et al., 1999; SCHEEREN et al., 2010).

A demanda por sementes de boa qualidade física, fisiológica e sanitária tem aumentado, e os produtores de sementes têm praticado a classificação das sementes de soja por tamanho após o processo de limpeza. Segundo Carvalho e Nakagawa (2000), as sementes de maior tamanho apresentam embriões bem formados, com maiores quantidades de reservas, sendo potencialmente as mais vigorosas, o que aumenta a probabilidade de sucesso no estabelecimento da plântula.

A viabilidade e o vigor das sementes, influenciam diretamente na taxa de emergência e emergência total, o tamanho de semente é outro componente da qualidade fisiológica que vem sendo avaliado. Apesar da não existência de provas concretas sobre sua vantagem, ela tem sido usada como propaganda pelos produtores de sementes (VINHAL-FREITAS et al., 2011). 
A velocidade e a uniformidade $\mathrm{da}$ semente na qualidade fisiológica da soja em emergência das plântulas dependem do vigor das sementes e das condições do ambiente. Em regiões tropicais é comum durante a safra ocorrer à indisponibilidade hídrica, principalmente na fase inicial, afetando o estabelecimento da cultura, que também é afetada pelo vigor das sementes, esses são agentes determinantes do processo de estabelecimento das plântulas no solo (PAIVA, 2007).

A germinação é um parâmetro de avaliação que considera condições ótimas de ambiente (VINHAL-FREITAS et al., 2011). A velocidade de germinação e emergência são aspectos limitantes para qualquer cultura, no entanto, na soja, em cultivares com menos de 120 dias de ciclo, isto é preponderante pela elevada associação entre o momento do fechamento do dossel e o rendimento (BARZOT'TO et al., 2012).

O vigor caracteriza-se pela habilidade de determinado lote de sementes, estabelecer plântulas normais em condições de campo (MOTERLE et al., 2011). Os testes de vigor são utilizados visando à identificação de diferenças associadas ao desempenho do lote de semente durante o armazenamento ou após a semeadura, para destacar lotes que tenham maior estabelecimento do estande sob várias condições ambientais (MARCOS FILHO; KIKUT; LIMA, 2009).

Ainda existe muita controvérsia em relação ao efeito do tamanho da semente de soja no desempenho da cultura, havendo a necessidade de pesquisas para o melhor esclarecimento do assunto. Desta maneira, o presente trabalho tem por objetivo verificar a influência do tamanho da diferentes períodos de armazenamento.

\section{MATERIAL E MÉTODOS}

O experimento em canteiro, foi conduzido no campo experimental situado na rua 57 , quadra 55, lote 05, Colina Park, e o experimento em laboratório na Faculdade Evangélica de Goianésia - FACEG, situados no município de Goianésia/GO. Região centro-oeste do país com clima tropical úmido. Foi utilizado a cultivar de soja, BMX. Bônus IPRO, classificada em três tamanhos: 5 mm com o lote de número 097/2017; peneira $6 \mathrm{~mm}$ com o lote de número 122/2017 e 7 mm com o lote de número 021/2017, mediante emprego de peneiras de crivos circulares. Cada tamanho foi considerado como um tratamento. Foram avaliados também 4 períodos de armazenamento: 21, 42, 63 e 84 dias.

\section{Testes de Germinação em BOD}

Germinadores: Foi realizado o teste de germinação em rolo de papel, utilizando a metodologia padrão descrita nas Regras para Análise de Sementes - RAS (BRASIL, 2009), para cada teste realizado foram realizadas quatro repetições com 50 sementes, para o tratamento que foi avaliado. As sementes foram acondicionadas em papel germitest umedecido à 2,5 vezes o peso do papel. Como superfície foram utilizadas duas folhas do papel e como cobertura apenas uma. Logo após, estas foram acondicionadas em germinadores (BOD) em temperatura constante de $25^{\circ} \mathrm{C}$ por 24 horas. Após sete dias do acondicionamento foi realizada a avaliação e contagem das plântulas normais. 


\section{Germinação em canteiros: Foram} utilizados canteiros de alvenaria preenchidos com duas partes de solo do tipo latossolo vermelho e uma parte de areia. Onde foram semeadas quatro repetições de 200 sementes cada, com 50 sementes por linha de aproximadamente um metro de comprimento por um metro de largura e três $\mathrm{cm}$ de profundidade. A irrigação foi realizada duas vezes ao dia de forma manual. A avaliação e contagem de plântulas foram realizadas 7 dias após a semeadura. Os parâmetros para avaliação seguiram os descritos nas Regras para Análise de Sementes - RAS (BRASIL, 2009).

\section{Testes de Vigor}

Para avaliação do vigor foram realizados 3 testes, sendo eles:

\section{Índice de velocidade de emergência: $\mathrm{O}$} teste é baseado no princípio de que os lotes de sementes que possuem a maior velocidade de emergência, possuem a capacidade de serem mais vigorosos. Então foi realizado o registro diariamente do número de plântulas emergidas, com parte aérea formada, até o nono dia, quando houve a estabilização da emergência. $O$ cálculo utilizado foi proposto por Maguire (1962), utilizando a seguinte fórmula:

$$
\begin{gathered}
\mathrm{IVE}=\mathrm{E} 1+\mathrm{E} 2+\ldots \\
\mathrm{N} 1+\mathrm{N} 2
\end{gathered}
$$

Onde:

IVE $=$ índice de velocidade de emergência

$\mathrm{E}=$ número de plântulas normais diariamente avaliadas

$\mathrm{N}=$ número de dias individualmente avaliados
Massa da matéria seca de plântula: Foi

realizado em conjunto com o teste de comprimento da plântula. Após a permanência prevista no germinador, as plântulas normais de cada tratamento foram retiradas e contadas. Os cotilédones foram removidos, e colocados em recipientes de alumínio, previamente tarados, separados por repetição, e, a seguir, postos para secar em estufa regulada a $80^{\circ} \mathrm{C}$, durante 24 horas. Após esse período as amostras foram retiradas da estufa e colocadas para esfriar em um dessecador. Depois de frios, os cotilédones foram pesados em balança de precisão. A massa de cada tratamento foi dividida pelo número de plântulas normais, o que resultou na massa média de matéria seca por plântula, expressa em $\mathrm{mg} /$ plântula (NAKAGAWA, 1999).

\section{Análise estatística}

O experimento foi conduzido em delineamento inteiramente casualizado com quatro repetições. Cada repetição foi composta por 200 sementes, sendo 50 sementes por linha. O experimento foi conduzido seguindo as recomendações técnicas para a cultura. A avaliação e contagem de plântulas foram realizadas 7 dias após a semeadura

Após a obtenção dos dados foi realizada a análise estatística pela análise da variância do tipo fatorial, e para comparação das médias dos tratamentos foi aplicado o teste de Tukey a 5\% de probabilidade.

\section{RESULTADOS E DISCUSSÃO}

Para as análises de variância realizadas, observou-se interação significativa entre os fatores: 
tamanho da semente e teste de germinação em laboratório; tamanho da semente e teste de germinação em canteiro; tamanho da semente e teste de vigor através da massa seca de plantas em canteiro; tamanho da semente e teste de vigor através da condutividade elétrica.

As médias das peneiras (Tabela 1), revelam superioridade das peneiras 6 e 7, em comparação a peneira 5. Isso demonstra que as sementes de tamanho maior, apresentam melhor taxa de germinação. Segundo Carvalho e Nakagawa (2000), as sementes de maior tamanho apresentaram embriões bem formados e com maiores quantidades de reservas, sendo potencialmente as mais vigorosas, o que aumenta a probabilidade de sucesso no estabelecimento da plântula.

Tabela 1. Interação da taxa de germinação em quatro datas distintas por três peneiras de semente de soja, cultivar BMX. Bônus IPRO e as médias de germinação das peneiras em teste de germinação em BOD no laboratório da FACEG, 2018.

\begin{tabular}{|c|c|c|c|c|c|}
\hline \multirow[t]{2}{*}{ Tratamento } & \multicolumn{4}{|c|}{ Período de armazenamento (Dias) } & \multirow{2}{*}{$\begin{array}{l}\text { Médias das } \\
\text { peneiras (\%) }\end{array}$} \\
\hline & 21 & 42 & 63 & 84 & \\
\hline Peneira 5 & $93,00 \mathrm{abA}$ & $97,00 \mathrm{aA}$ & $88,00 \mathrm{bB}$ & $78,50 \mathrm{bC}$ & $89,13 \mathrm{~B}$ \\
\hline Peneira 6 & $96,50 \mathrm{aA}$ & $97,50 \mathrm{aA}$ & 94,50 aA & $91,50 \mathrm{aA}$ & $95,00 \mathrm{~A}$ \\
\hline Peneira 7 & $96,00 \mathrm{aA}$ & $98,50 \mathrm{aA}$ & $95,00 \mathrm{aA}$ & $83,00 \mathrm{bB}$ & $93,13 \mathrm{~A}$ \\
\hline $\mathrm{CV} \%$ & 3,86 & & & & \\
\hline
\end{tabular}

Médias seguidas pela mesma letra minúscula na horizontal e letra maiúscula na coluna vertical, não diferem entre si pelo teste de Tukey a 5\% de probabilidade

Observou-se diferenças significativas para a interação da germinação com o tamanho das sementes. As sementes da peneira 6 e 7 no período de armazenamento de 63 dias, apresentaram taxas de germinação superiores as da peneira 5 . As sementes da peneira 6 armazenadas por 84 dias apresentaram taxa de germinação $10 \%$ superior que as das peneiras 5 e 7 . As sementes da peneira 6 mantiveram uma performance uniforme de germinação para todos os períodos avaliados, ao contrário da peneira 7 que apresentou queda de germinação aos 84 dias. A queda na taxa de germinação para a peneira 5 ocorreu a partir de 63 dias do armazenamento.

Resultados divergentes foram obtidos por Pádua et al. (2010), que avaliando três cultivares de soja observou que as sementes de maior tamanho (7,0 mm), apresentaram melhores resultados. E por Vendrame (2012), onde o tamanho da semente não afetou a germinação.

O limite estabelecido para a comercialização de sementes de soja é que essas apresentem taxas de germinação maiores que 85\% (MARCOS FILHO, 2009). Taxa que não foi não foi atingida para as peneiras 6 e 7 quando as 
sementes foram armazenadas por 84 dias. Durante a realização do teste para as sementes armazenadas por esse período ocorreu falta de iluminação durante algumas horas na encubadora, o que pode ter ocasionado a baixa taxa de germinação. Segundo Fonseca (2007), a soja é uma planta sensível à duração do período luminoso. Assim, o florescimento das plantas é consequência direta do mesmo, e corresponde à fase fisiológica que determina o desempenho final da cultura, com relação à produção.

Para os testes de germinação em canteiro (Tabela 2), as sementes da peneira 6 foram as que apresentaram melhor desempenho médio entre as peneiras avaliadas. Enquanto que as peneiras 5 e 7, não diferiram estaticamente entre si. $\mathrm{O}$ resultado encontrado corrobora com o resultado obtido pelo teste em laboratório, onde as sementes da peneira 6 também apresentaram melhores médias que as demais. Para a interação da germinação em canteiro e tamanho das sementes, observou-se que a peneira 6 apresentou melhor desempenho em todas as avaliações realizadas, mantendo uma performance uniforme de germinação.

Tabela 2. Interação da taxa de germinação em quatro datas distintas por três peneiras de semente de soja, cultivar BMX. Bônus IPRO e as médias de germinação das peneiras em teste de germinação em canteiro, 2018.

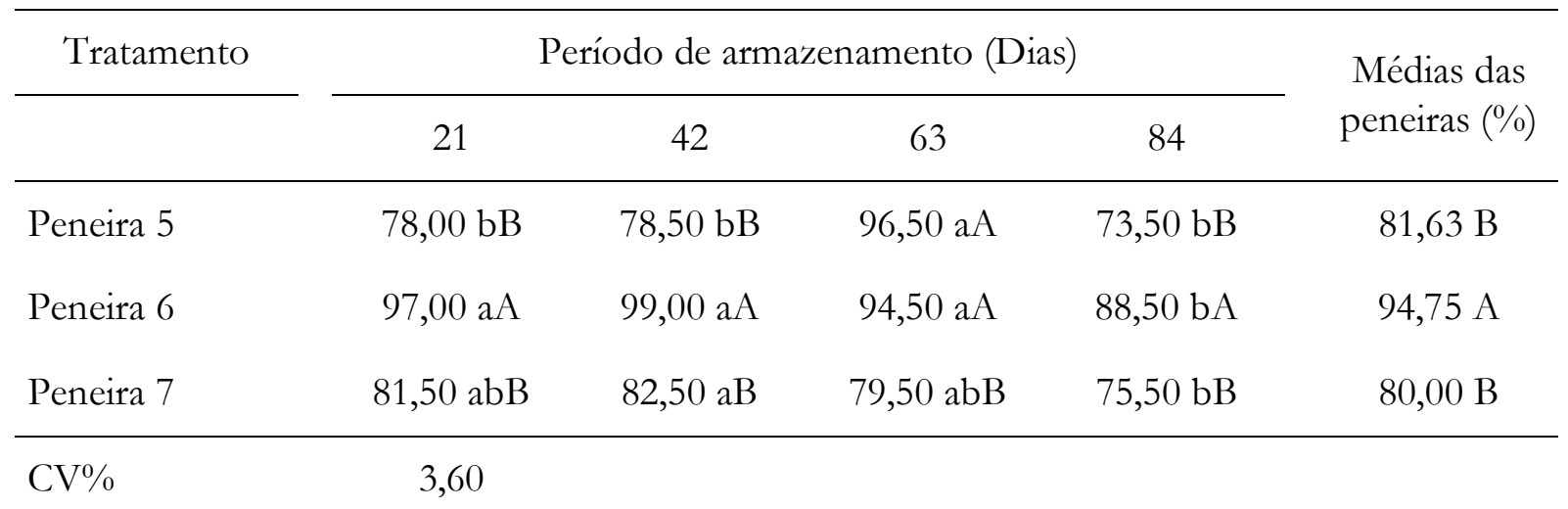

Médias seguidas pela mesma letra minúscula na horizontal e letra maiúscula na coluna vertical, não diferem entre si pelo teste de Tukey a 5\% de probabilidade

Segundo Carvalho e Nakagawa (2000) a máxima qualidade da semente de soja é alcançada quando ela atinge a maturidade fisiológica, e após essa a semente começa a deteriorar. Entre os diversos fatores que afetam a deterioração está o tamanho da semente. Os resultados revelam que para a peneira 5 , as maiores taxas de germinação foram obtidas para as sementes armazenadas por 63 dias, para os demais períodos de armazenamento não ocorreram diferenças significativas. Para as peneiras 6 e 7 as maiores taxas foram obtidas com o período de armazenamento de 42 dias. A prolongação do período de armazenamento resultou em menores taxas de germinação, devido à maior deterioração da semente.

Os resultados do teste de vigor através da massa seca de plantas em canteiro (Tabela 3), demonstram um melhor desempenho das sementes da peneira 6 para as médias das peneiras. 


\begin{abstract}
Resultados divergentes foram obtidos por Pádua et sendo capazes de suportar melhor as adversidades al., (2010) observaram que as sementes maiores do ambiente (SCHEEREN et al., 2010). Além provenientes da peneira 7 apresentaram maior disso, plantas provenientes das sementes de alto vigor quando comparadas com as da peneira 6. As vigor apresentam maior área foliar e produção de sementes consideradas de alto vigor, normalmente matéria seca (KOLCHINSKI; SCHUCH; PESKE, apresentam germinação mais rápida e uniforme, 2006).
\end{abstract}

Tabela 3. Interação da taxa de massa de matéria seca da plântula em quatro datas distintas por três peneiras de semente de soja, cultivar BMX. Bônus IPRO e as médias da massa de matéria seca de plântula das peneiras em laboratório da FACEG, 2018.

\begin{tabular}{|c|c|c|c|c|c|}
\hline \multirow[t]{2}{*}{ Tratamento } & \multicolumn{4}{|c|}{ Período de armazenamento (Dias) } & \multirow{2}{*}{$\begin{array}{l}\text { Médias das } \\
\text { peneiras }(\%)\end{array}$} \\
\hline & 21 & 42 & 63 & 84 & \\
\hline Peneira 5 & $13,20 \mathrm{aC}$ & $12,52 \mathrm{aC}$ & $10,77 \mathrm{bC}$ & $7,950 \mathrm{cC}$ & $11,11 \mathrm{C}$ \\
\hline Peneira 6 & $22,03 \mathrm{cA}$ & $27,36 \mathrm{aA}$ & $23,21 \mathrm{bA}$ & $17,73 \mathrm{dA}$ & $22,58 \mathrm{~A}$ \\
\hline Peneira 7 & $17,96 \mathrm{aB}$ & $16,72 \mathrm{bB}$ & $14,78 \mathrm{cB}$ & $14,93 \mathrm{cB}$ & $16,10 \mathrm{~B}$ \\
\hline $\mathrm{CV}^{0} \%$ & 3,32 & & & & \\
\hline
\end{tabular}

Médias seguidas pela mesma letra minúscula na horizontal e letra maiúscula na coluna vertical, não diferem entre si pelo teste de Tukey a 5\% de probabilidade

A prolongação do período de estatísticas entre as três classes de sementes quando armazenamento para todas as peneiras avaliadas avaliado o comprimento de plântulas. causou redução na taxa de massa de matéria seca da plântula. A taxa de matéria seca da peneira foi Os maiores IVE foram observados no maior para as sementes da peneira 6 e menor para período de armazenamento de 21 dias. Isso devea peneira $5 \mathrm{em}$ todos os períodos de se ao fato da velocidade de germinação ser armazenamento.

O índice de velocidade de germinação com reduzida com o avanço da deterioração da semente (GUEDES et al., 2009). As plântulas com maior base no número das plântulas emergidas (Gráfico 1) foi maior para as sementes da peneira 6 . Resultado divergentes foram obtidos por Cangussú et al. (2013) onde não foram detectadas diferenças

IVE possuem maior desempenho e, em contrapartida, maior capacidade de resistir a estresse, o que pode vir a interferir no crescimento e no desenvolvimento da planta (JUVINO et al., 2014). 


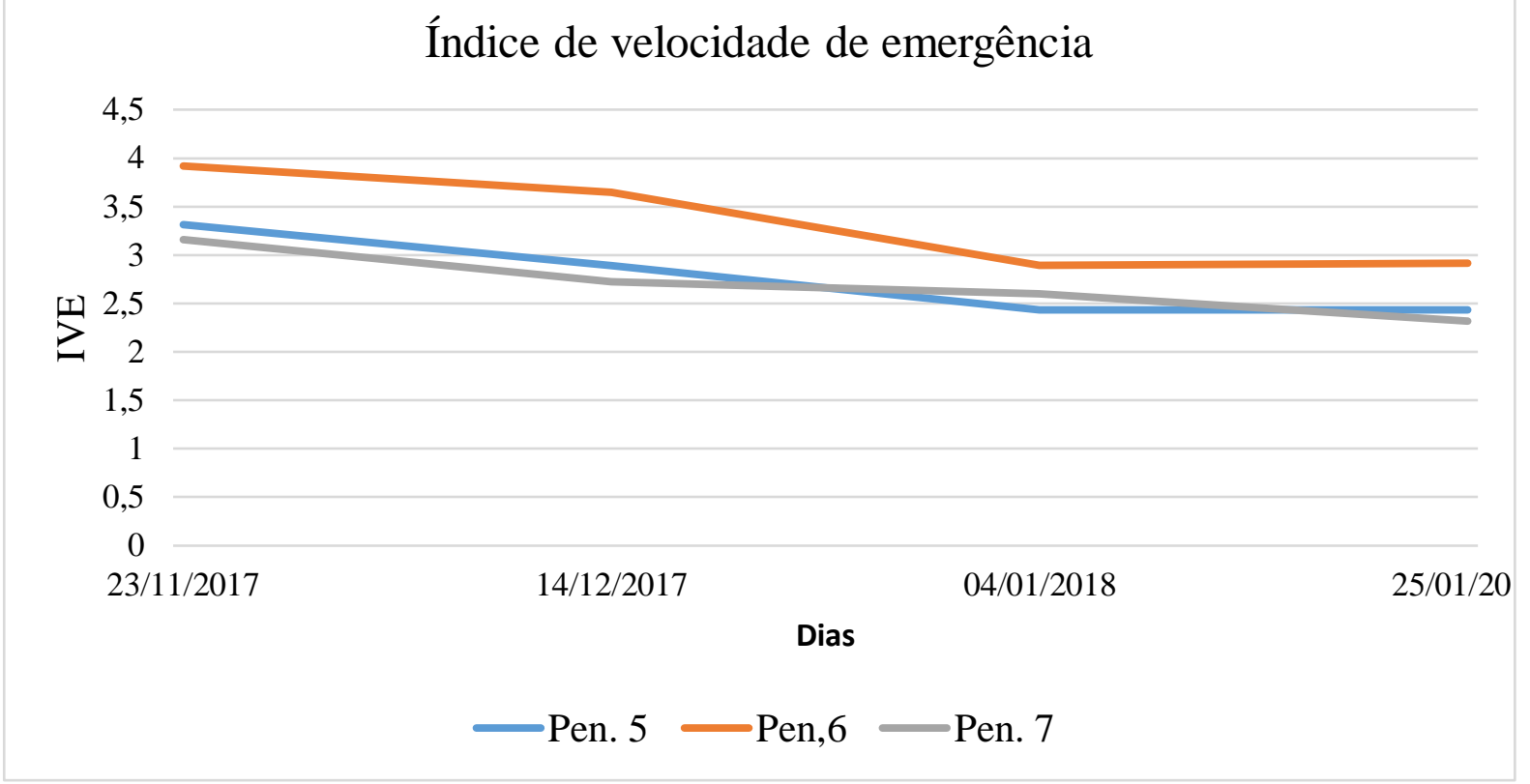

Figura 1. Desenvolvimento do Índice de Velocidade de Emergência (IVE) de plântulas na interação de 3 peneiras de soja, avaliadas em 4 períodos distintos do armazenamento, na FACEG, 2018.

A padronização dos lotes de sementes possibilita a obtenção de uma semeadura uniforme em campo, gerando economia na quantidade de sementes e facilitando a regulagem das semeadoras. Outro aspecto importante da uniformização da lavoura é a possibilidade de realizar plantios com baixas densidades que vem sendo amplamente adotado devido a problemas fitossanitários e acamamento de plantas (GUEDES et al., 2009).

\section{CONCLUSÕES}

- A classificação das sementes possui influência direta sobre a taxa de germinação e vigor das sementes.

- A influência do tempo de armazenamento na germinação e vigor irá depender do tamanho da semente.

- As sementes da peneira de $6 \mathrm{~mm}$ apresentaram maiores taxas de germinação.

REFERÊNCIAS BIBLIOGRÁFICAS

BARZOT'TO, F.; FACCO, L.; MAT'TIONI, N.; FARIAS, G. J.; SEGALIN, S. Resposta de cultivares de soja à germinação sob temperaturas sub ótimas. In: SEMINÁRIO ESTADUAL DE EDUCAÇÃO BÁSICA, 16, 2012, Santa Maria. Anais ... Santa Maria: SEPE, 2012. P. 1-10.

BRACCINI, A. L.; REIS, M. S.; SEDIYAMA, C. S.; SCAPIM, C. A.; BRACCINI, M. C. L. Avaliação da qualidade fisiológica de sementes de soja, após o processo de hidratação-desidratação e envelhecimento acelerado. Pesquisa Agropecuária Brasileira, Brasília, v. 34, n. 6, p.1052-1066, jun. 1999.

BRASIL. Ministério da Agricultura, Pecuária e Abastecimento. Regras para análise de sementes. Brasília: SNDA/DNDV/CLAV, p 399, 2009.

CANGUSSÚ, L. V. DE S.; DAVID, A. M. S. DE S.; AMARO, H. T. R.; ASSIS, M. DE O. Efeito do tamanho de sementes no desempenho fisiológico de feijoeiro. Pesq. Agrop. Gaúcha, Porto Alegre, v. 19, n. 1, p.73-81, jan. 2013. 
CARVALHO, N. M.; NAKAGAWA, J. Sementes: ciência, tecnologia e produção. 4.ed. Jaboticabal: FUNEP, 2000, 588p.

CONAB. COMPANHIA NACIONAL DE ABASTECIMENTO. Acompanhamento de safra brasileiro - grãos: Nono levantamento, abril 2018 - safra 2017/2018. Brasília: Companhia Nacional de Abastecimento. 2018.

\section{FONSECA, N. R. Qualidade fisiológica e} desempenho agronômico de soja em função do tamanho das sementes. 2007. 80 f. Tese (Doutorado) - Curso de Agronomia, Universidade Estadual Paulista "Júlio de Mesquita Filho", Botucatu, 2007.

GUEDES, ROBERTA S.; ALVES, E. U.; GONÇALVES, E. P.; SANTOS, S. DO R. N.; LIMA, C. R. Testes de vigor na avaliação da qualidade fisiológica de sementes Erythrina velutina Willd. (FABACEAE - PAPILIONOIDEAE). Ciência e Agrotecnologia, Lavras, v. 33, n. 5, p.1360-1365, out. 2009.

HIRAKURI, M. H.; LAZZAROTTO, J. J. O agronegócio da soja nos contextos mundial e brasileiro. Londrina: Embrapa, 2014. 37 p.

JUVINO, A. N. K.; RESENDE, O.; COSTA, L. M.; SALES, J. DE F. Vigor da cultivar BMX Potência RR de soja durante o beneficiamento e períodos de armazenamento. Revista Brasileira de Engenharia Agrícola e Ambiental, Campina Grande, v. 18, n. 8, p.844-850, jan. 2014.

MARCOS FILHO, J.; KIKUT, A. L. P.; LIMA, L. B. Métodos para avaliação do vigor de sementes de soja, incluindo a análise computadorizada de imagens. Revista

Brasileira de Sementes, Piracicaba, v. 31, n. 1, p.102-112, jan. 2009.

MOTERLE, L. M.; SANTOS, R. F.; SCAPIM, C. A.; BRACCINI, A. L.; BONATO, C. M; CONRADO T. Efeito de biorregulador na germinação e no vigor de sementes de soja. Revista Ceres, Viçosa, v. 58, n. 5, p.651660, out. 2011.

PADUA, G. P. de; ZITO, R. K.; ARANTES, N. E.; FRANCA NETO, J. de B. Influência do tamanho da semente na qualidade fisiológica e na produtividade da cultura da soja. Revista Brasileira de Sementes, Uberaba, v. 32, n. 3, p.9-16, jan. 2010.

\section{PAIVA, A. S. Disponibilidade hídrica na} germinação de sementes e no crescimento de plântulas da leguminosa forrageira Macrotyloma axillare (E. Mey) Verdc. cv. Java. 2007. 99 f. Tese (Doutorado) - Curso de Agronomia, Universidade Estadual Paulista "Júlio de Mesquita Filho”, Jaboticabal, 2007.

SANTOS, A. S.; SOUZA, E. M.; FÉBOLI, A.; NOGUEIRA, D. C. Testes de vigor em sementes de três cultivares de soja. Rev. Conexão Eletrônica, Três Lagoas, v. 14, n. 1, p.674-685, jan. 2017.

SCHEEREN, B. R.; PESKE, S. T., SCHUCH, L. O. B.; BARROS, A. C. A. Qualidade fisiológica e produtividade de sementes de soja. Revista Brasileira de Sementes, Londrina, v. 32, n. 3, p.35-41, 2010.

VENDRAME, R. J. Qualidade de semente de soja em função do tamanho da semente e da cultivar. 2012. 26 f. Dissertação (Mestrado) - Curso de Ciência e Tecnologia de Sementes, Universidade Federal de Pelotas, Pelotas, 2012.

VIEIRA, E. H. N.; RAVA, C. A. Sementes de feijão: produção e tecnologia / editado por Edson Herculano Neves Vieira, Carlos Augustin Rava. - Santo Antônio de Goiás: Embrapa Arroz e Feijão, p. 29-34. 2000.

VINHAL-FREITAS, I. C.; NUNES JUNIOR, J. E. G.; SEGUNDO, J. P.; VILARINHO, M. S. Germinação e vigor de sementes de soja classificadas em diferentes tamanhos. Agropecuária Técnica, Ituiutaba, v. 32, n. 1, p.108-114, jan. 2011. 